\title{
WIDENING ACCESS TO UNDERGRADUATE PHYSIOTHERAPY EDUCATION IN SOUTH AFRICA - POINTERS FROM STUDENTS' RECORDS
}

\begin{abstract}
In response to the state mandate to improve access and equity in higher education, the admission policy of universities in South Africa (SA) currently employs measures for the redress of past inequalities and racial injustices. As there is no information on the processes to widen access to undergraduate physiotherapy education program in $S A$, the aim of this reported study was to search for pointers from students' records in one local university, situated in the Western Province of SA, that would inform the development of strategies that will widen the access for previously disadvantaged population groups and ensure successful academic outcomes. The records of six cohorts of students who earlier applied for and later enrolled in the undergraduate physiotherapy program between the years 2000 and 2005 were retrospectively reviewed. Information pertaining to access, student characteristics, and academic persistence was extracted, reviewed and analysed descriptively. During the period reviewed, approximately equal numbers of Black and non-Black students applied for admission to the program. The proportion of Black applicants meeting minimum admission requirements was less than half of the White/Asian applicants. Less than 50\% (105/212) of the offers made to Black applicants were accepted. Forty one percent (43/105) of the enrolled Black students successfully completed the program within the minimum 4 years compared to $75.5 \%$ (145/192) of the White/Asian students. Strategies should be implemented to increase awareness and recruitment, improve enrolment rates, and improve retention and throughput for Black students in the undergraduate physiotherapy program of a historically "white" SA university.
\end{abstract}

\section{KEY WORDS: WIDENING ACCESS, PHYSIOTHERAPY, UNDERGRADUATE EDUCATION.}

\section{INTRODUCTION}

South Africa (SA) is a developing country characterised by a rich culture, significant social diversity and a high degree of inequality (Louw et al 2007). Estimated to be around 48.9 million in 2009, the South African population comprises of four main racial groups, namely: "African" (79.3\%), "White" (9.1\%), "Coloured" (9.0\%), and "Asian" $(2.6 \%)$. The demarcation of these racial groups has remained consistent with the original racial classifications which were first introduced during the apartheid era (Khalfani and Zuberi 2001). The entirety of the government's intention at the time of apartheid was largely captured by the passing of the Bantu Education Act in 1953 and the uttering of the following words by the then Minister of Native Affairs (Hendrik Verwoerd):

"My department's policy is that education should stand with both feet in the reserves and have its roots in the spirit and being of Bantu society... the Bantu must be guided to serve his own community in all respects. There is no place for him in the European community above the level of certain forms of labour. Within his own community, however, all doors are open. For that reason it is of no avail for him to receive a training which has as its aim absorption in the European community, where he cannot be absorbed" (Nekhwevha 1999).

The passing of the Bantu Education Act (1953), along with other ramifications, largely contributed to the establishment of approximately 36 higher education institutions around the country (Ensor 2002). Although the large number of higher education institutions may be impressive for a developing country, it is the significant variation in the quality and type of amenities provided between the institutions, which are a direct reflection of the impact apartheid had on South Africans and their education (van der Westhuizen 2005). Undoubtedly, apartheid was responsible for the development of racially fragmented, unequal and dysfunctional systems within the society, including the education and health sectors (Cross et al 2002; Mooney and McIntyre 2008). The inequitable higher education systems, as well as the inaccessibility to higher education institutions for non-white population groups, therefore limited human resource development in SA (Winberg 2006). Albeit a few of the differentiating systems between the
Correspondence Author:
Prof SL Amosun,
Division of Physiotherapy,
School of Health and
Rehabilitation Sciences,
Faculty of Health Sciences,
University of Cape Town,
South Africa
Email: seyi.amosun@uct.ac.za 
racially-demarcated groups have not been completely eradicated (Cross et al 2002), dramatic changes have occurred in the higher education sector since the transition of SA to democracy in 1994 (Mooney and McIntyre 2008). The main reason of applying these changes was to eliminate the legacy of the raciallyfragmented and unequal education systems which existed, and to steer the country towards the goals of economic development, social reconstruction and equity (Subotzky 2010).

In an attempt to achieve these goals, it was suggested that the enrolment of new undergraduate students, the recruitment of the university staff, as well as the distribution of the human resources across the country, should reflect the diversity and social composition of the broader South African population. The reorganisation, standardization and redistribution of the previously raciallyfragmented higher education institutions (Taylor and Harris 2004) was further reinforced by the comprehensive redesign of the higher education curricula; namely the National Qualifications Framework (NQF), which was operationalised using an outcome-based education (OBE) system at high school level (Ensor 2002). The OBE system was envisaged to meet the needs of all students regardless of their environment, ethnicity, economic status, or disabling condition.
Similarly, in 1997, the Department of Health in SA formulated the National Health Policy which focused on promoting equity, accessibility and utilization of health services across all ethnic groups (Department of Health 1997). The policy specifically included the training of additional human resources for the health sector (Department of Health 1997). In 2009, the Health Professions Council of South Africa (HPCSA) revealed that a total of 5081 physiotherapists registered with the council the previous year, and delivered services to approximately 48.9 million people across SA (HPCSA 2009). From this annual report it was however observed that the non-white population groups remained under-represented in the profession. It was further reported that during 2008, a total of 1648 physiotherapy students were registered in eight universities offering the undergraduate physiotherapy program (HPCSA 2009). Similarly the report revealed that the proportion of students from the white population group enrolled in the undergraduate physiotherapy program remained the highest, as in previous years (HPCSA 2009). The higher proportion of the white population group compared to the nonwhite population groups continued to follow a similar trend on graduation (South African Qualifications Authority 2007). Between 1995 and 2004, approximately $23.8 \%(634 / 2697)$ of all nationally graduating physiotherapists belonged to the Coloured and African population groups (Table 1). Therefore, in a bid to ensure fair distribution of skills training across racial groups, graduating more physiotherapists from the under-represented population groups would be desirable.

In response to this need, the Faculty of Health Sciences at the University of Cape Town (UCT), developed a strategic plan in 1999 which included the transformation of the undergraduate curricula for medicine, physiotherapy, occupational therapy, audiology and speech therapy. The aim of the transformation was essentially to align the undergraduate programs with the aspirations of the country to increase access to higher education for the previously disadvantaged population groups (Duncan et al 2006). Historically classified as one of the "white" universities of SA, UCT has always professed to be an "open" university. However, in the past, only a token number of students from non-white population groups were enrolled into the undergraduate physiotherapy program each year. This was generally attributed to the admission criteria being too competitive and the fact that applicants' IQ scores were taken into account (Jaholkowski 1979; Kemp and Gounden 2000). In anticipation of the first cohort of OBE school learners who would enter tertiary education in 2009, the plan to particularly widen access to

Table 1: Graduation trends in undergraduate physiotherapy education in South Africa (1995-2004)

(South African Qualification Authority 2007)

\begin{tabular}{|c|c|c|c|c|}
\hline & \multicolumn{4}{|c|}{ Graduation trends by population groups } \\
\hline & African & Coloured & Asian & White \\
\hline 1995 & 31 & 11 & 11 & 155 \\
\hline 1996 & 32 & 23 & 13 & 167 \\
\hline 1997 & 24 & 24 & 19 & 168 \\
\hline 1998 & 35 & 25 & 31 & 172 \\
\hline 1999 & 40 & 25 & 36 & 180 \\
\hline 2000 & 47 & 24 & 48 & 176 \\
\hline 2001 & 40 & 26 & 26 & 170 \\
\hline 2002 & 36 & 37 & 50 & 171 \\
\hline 2003 & 54 & 32 & 50 & 189 \\
\hline 2004 & 44 & 33 & 41 & 181 \\
\hline
\end{tabular}


the undergraduate physiotherapy program for previously disadvantaged population groups, was commenced at UCT in 2003.

It is acknowledged that to widen access into an academic program for previously disadvantaged populations groups, the profile and specific needs of the student body anticipated to enroll in the program should be considered. Owing to the apartheid Bantu education system, a vast majority of students currently entering university in SA are from low socioeconomic backgrounds, are first generation students, and are members of population groups at risk of dropping out (Strydom et al 2010). As a result, a large proportion of entering students present with two or more of the risks associated with university drop put, and Black African students still constitute the majority of the drop puts. Therefore, prior to developing a strategy to widen access to the undergraduate physiotherapy program at UCT, preliminary steps were taken to identify the specific aspects or issues which could assist in guiding the development process of the strategy. These preliminary steps were informed by the study of Scott et al (2007) which reported that the analysis of students' throughput rates located higher education outputs between much broader conceptual issues i.e. access and equity, and the quality of the educational process. This approach provided an opportunity to reflect on the relationship between access, equity and quality; the theoretical underpinnings; and the practical tensions and challenges faced by different stakeholders in the implementation of strategies to improve access to education, teaching and learning (Scott et al 2007). Therefore, the purpose of this manuscript is to report the outcomes of the review of available records of students who applied for admission and students who enrolled in the undergraduate physiotherapy program at UCT from 2000 to 2005 .

\section{METHODS \\ Institutional setting}

The admission policy of UCT provides appropriate measures for the redress of past inequalities in SA. Traditionally, the high school subjects required for admission into the UCT undergraduate physiotherapy program included English, Mathematics, and Biology and/ or Physical Science, and admission was based on performance in the National Senior Certificate examination at the end of high school career. In its attempt to achieve the ultimate goal of filling a class with a diverse group of students reflecting the various racial population groupings in the country, the university utilises three main tools to select the best qualified students, namely: the mark obtained in the National Senior Certificate examination; the National Benchmark Test which assesses comprehension of English language, and problem solving and reasoning skills; and a biographical questionnaire which assesses non-academic skills including community involvement and leadership qualities. As the university considers the White and Asian population groups as privileged, applicants from these population groups required at least 43 points to stand a fair chance of being admitted into the undergraduate physiotherapy program in 2009. Applicants from the African and Coloured population groups required at least 34 points to stand a chance of being admitted.

\section{Procedure and Analysis}

The official records for the 2000 to 2005 cohorts of students who applied for admission into the undergraduate physiotherapy program or enrolled in the program were retrieved from the database of the Institutional Planning Department of UCT and the Undergraduate Office in the Faculty of Health Sciences, and captured in a spreadsheet. The information

Table 2: Racial profile of applicants meeting minimum admission requirements among six cohorts of applicants (years 2000 to 2005)

\begin{tabular}{|c|c|c|c|c|c|c|c|c|}
\hline \multirow[b]{2}{*}{ Cohort } & \multicolumn{4}{|c|}{ Black applicants } & \multicolumn{4}{|c|}{ White/Asian applicants } \\
\hline & African & Coloured & Total & $\begin{array}{c}\text { Meet min } \\
\text { requirement } \\
(\%)\end{array}$ & White & Asian & Total & $\begin{array}{l}\text { Meet min } \\
\text { requirement } \\
(\%)\end{array}$ \\
\hline 2000 & 130 & 43 & 173 & $37 / 173(21.4 \%)$ & 183 & 79 & 262 & $\begin{array}{l}125 / 262 \\
(47.7 \%)\end{array}$ \\
\hline 2001 & 150 & 43 & 193 & $39 / 193(20.2 \%)$ & 180 & 85 & 265 & $\begin{array}{l}125 / 265 \\
(47.2 \%)\end{array}$ \\
\hline 2002 & 192 & 66 & 258 & $47 / 258(18.2 \%)$ & 180 & 97 & 277 & $\begin{array}{l}121 / 277 \\
(43.7 \%)\end{array}$ \\
\hline 2003 & 169 & 74 & 243 & $55 / 243(18.6 \%)$ & 163 & 71 & 234 & $\begin{array}{l}126 / 234 \\
(53.8 \%)\end{array}$ \\
\hline 2004 & 171 & 45 & 216 & $59 / 216(27.3 \%)$ & 140 & 71 & 211 & $135 / 211(64 \%)$ \\
\hline 2005 & 143 & 73 & 216 & $89 / 216(41.2 \%)$ & 140 & 65 & 205 & $\begin{array}{l}144 / 205 \\
(70.2 \%)\end{array}$ \\
\hline Total & 955 & 344 & 1299 & $\begin{array}{l}326 / 1299 \\
(25.1 \%)\end{array}$ & 986 & 468 & 1454 & $\begin{array}{l}776 / 1454 \\
(53.4 \%)\end{array}$ \\
\hline
\end{tabular}


captured for all students who applied for admission included population groupings and matriculation points obtained. For those who enrolled in the program, the same information plus length of time taken to successfully complete the program was captured. Though the use of school matriculation results as the primary determinant for university entrance is common is SA and many other countries, however the ability of the results to predict student success has been reported to be quite limited in SA generally (Fraser and Killen 2003), and in physiotherapy undergraduate program specifically (Mbambo 2005). As our study did not seek to identify the predictors of academic success in undergraduate physiotherapy program at UCT, the data captured was not analysed to identify possible predictors of retention or success in the program. In line with the admission policy of the university, the data for the privileged population groups were combined (White and Asian), while those of the less privileged groups (Africans and Coloureds) were combined for analysis. The term "Black" is used to refer to persons historically classified as African and Coloured (Khalfani and Zuberi 2001).

Ethical approval was obtained from the Research Ethics Committee of the Faculty of Health Sciences of UCT.

\section{RESULTS}

A total of 2753 applications from racially diverse population groups were received from South Africans over the review period (Table 2), an average of 458 applications per year. Applications from non-South African students were excluded from analysis. The proportion of Black applicants was 47.2\% (1299/2753), with African applicants accounting for over $73.5 \%(955 / 1299)$. The proportion of White/Asian applicants was $52.8 \%$ (1454/2753), with White applicants accounting for more than two-thirds $(986 / 1454)$. However only $40 \%(1102 / 2753)$ of the total applicants met the minimum requirements for admission, of which 29.6\%

Table 3: Racial profile of applicants who enrolled in the program $(n=1102)$

\begin{tabular}{|l|l|l|l|l|l|l|l|l|}
\hline & \multicolumn{3}{|l}{ Black with min requirements (n=326) } & \multicolumn{3}{l|}{ White/Asian with min requirements (n=776) } \\
\hline Cohort & $\begin{array}{l}\text { Offers } \\
\text { to } \\
\text { African }\end{array}$ & $\begin{array}{l}\text { Offers to } \\
\text { Coloured }\end{array}$ & $\begin{array}{l}\text { Total }(\% \text { of } \\
\text { minimum } \\
\text { requirement) }\end{array}$ & $\begin{array}{l}\text { Enrolled } \\
\text { (\% of offers) }\end{array}$ & $\begin{array}{l}\text { Offers } \\
\text { to } \\
\text { White }\end{array}$ & $\begin{array}{l}\text { Offers } \\
\text { to } \\
\text { Asian }\end{array}$ & $\begin{array}{l}\text { Total } \\
\text { (\% of minimum } \\
\text { requirement) }\end{array}$ & $\begin{array}{l}\text { Enrolled } \\
(\% \text { of offers) }\end{array}$ \\
\hline 2000 & 17 & 13 & $30 / 37(81.1 \%)$ & $8 / 30(26.7 \%)$ & 39 & 7 & $46 / 125(36.8 \%)$ & $30 / 46(65.2 \%)$ \\
\hline 2001 & 19 & 15 & $34 / 39(87.2 \%)$ & $8 / 34(23.5 \%)$ & 38 & 10 & $48 / 125(38.4 \%)$ & $28 / 48(58.3 \%)$ \\
\hline 2002 & 28 & 16 & $44 / 47(93.6 \%)$ & $19 / 44(43.2 \%)$ & 28 & 9 & $37 / 121(30.6 \%)$ & $23 / 37(62.1 \%)$ \\
\hline 2003 & 17 & 21 & $38 / 55(69.1 \%)$ & $18 / 38(47.4 \%)$ & 44 & 10 & $54 / 126(42.9 \%)$ & $37 / 54(68.5 \%)$ \\
\hline 2004 & 21 & 14 & $35 / 59(59.3 \%)$ & $33 / 35(94.3 \%)$ & 47 & 10 & $57 / 135(42.2 \%)$ & $40 / 57(70.2 \%)$ \\
\hline 2005 & 12 & 19 & $31 / 89(34.8 \%)$ & $19 / 31(61.3 \%)$ & 38 & 15 & $53 / 144(36.8 \%)$ & $34 / 53(64.2 \%)$ \\
\hline Total & 114 & 98 & $\mathbf{2 1 2 / 3 2 6 ( 6 5 \% )}$ & $105 / 212(49.5 \%)$ & 234 & 61 & $295 / 776(38 \%)$ & $192 / 295(65.1 \%)$ \\
\hline
\end{tabular}

Table 4: Racial profile of students who successfully completed the program $(n=225)$

\begin{tabular}{|c|c|c|c|c|c|c|}
\hline \multirow[b]{2}{*}{ Duration (yrs) } & \multicolumn{3}{|c|}{ Black $(n=105)$} & \multicolumn{3}{|c|}{ White/Asian $(n=192)$} \\
\hline & 4 & $4+1$ or 2 & $\begin{array}{l}\text { Total (\% of } \\
\text { enrolment) }\end{array}$ & 4 & $4+1$ or 2 & $\begin{array}{l}\text { Total ( } \% \text { of } \\
\text { enrolment) }\end{array}$ \\
\hline 2000 & 5 & 0 & $5 / 8 \quad(62.5 \%)$ & 24 & 0 & $24 / 30(80 \%)$ \\
\hline 2001 & 1 & 5 & $6 / 8 \quad(75 \%)$ & 22 & 3 & $25 / 28(89.3 \%)$ \\
\hline 2002 & 7 & 10 & $17 / 19(89.5 \%)$ & 19 & 3 & $22 / 23(95.7 \%)$ \\
\hline 2003 & 10 & 3 & $13 / 18(72.2 \%)$ & 32 & 2 & $34 / 37(91.9 \%)$ \\
\hline 2004 & 10 & 9 & $19 / 33(57.6 \%)$ & 25 & 2 & $27 / 40(67.5 \%)$ \\
\hline 2005 & 10 & 0 & $10 / 19(52.6 \%)$ & 23 & 0 & $23 / 34(67.6 \%)$ \\
\hline Total & $43(41 \%)$ & $27(25.7 \%)$ & $70 / 105(66.7 \%)$ & $145(75.5 \%)$ & $10(5.2 \%)$ & $155 / 192(80.7 \%)$ \\
\hline
\end{tabular}

Table 5: Profile of $\mathbf{1}^{\text {st }}$ year undergraduate physiotherapy students in the University of Cape Town (2008-2010)

\begin{tabular}{|l|r|r|r|r|r|r|}
\hline & \multicolumn{1}{|l|}{ Total intake } & \multicolumn{1}{l|}{ African } & \multicolumn{1}{l|}{ Coloured } & \multicolumn{1}{l|}{ Indian/Asian } & \multicolumn{1}{l|}{ White } & Non South African \\
\hline 2008 & 58 & $14 \%$ & $46 \%$ & $2 \%$ & $38 \%$ & $0 \%$ \\
\hline 2009 & 67 & $30 \%$ & $27 \%$ & $3 \%$ & $40 \%$ & $0 \%$ \\
\hline 2010 & 62 & $34 \%$ & $32 \%$ & $3 \%$ & $31 \%$ & $0 \%$ \\
\hline
\end{tabular}


(326/1102) were Black applicants. The proportions of Black applicants meeting minimum requirements for admission varied from $18.2 \%(47 / 258)$ in the 2002 cohort to $41.2 \%(89 / 216)$ in the 2005 cohort. Similarly the proportion of White/Asian applicants meeting minimum requirements for admission ranged from $43.7 \%(121 / 277)$ in the 2002 cohort to $70.2 \%(144 / 205)$ in the 2005 cohort. Overall, 25.1\% (326/1299) of Black applicants and 53.4\% (776/1454) of White/Asian applicants met the minimum requirements.

Of the 1102 South African applicants who met the minimum requirements for admission, offers were made to only 507 applicants (46\%) in the six cohorts (Table 3). Admission offers were made to $65.0 \%$ of the 326 Black applicants and $38.0 \%$ of White/Asian applicants who met minimum admission requirements. However, only 58.6\% (297/507) of total admission offers made enrolled in the program. Overall, 49.5\% (105/212) of the Black applicants offered admission enrolled in the program, increasing from $23.5 \%(8 / 34)$ in 2001 cohort to $94.3 \%(33 / 35)$ in 2004 cohort. Similarly, over $65 \%(192 / 295)$ of the offers made to White/Asian applicants were taken up, ranging from $58.3 \%(28 / 48)$ in the 2001 cohort to $70.2 \%(40 / 47)$ in the 2004 cohort.

Overall, 225 of the 297 registered students (75.8\%) successfully completed the program within four to six years (Table 4), of which 31.1\% (70/225) were Black students. Only two-thirds (70/105) of the Black students completed the program successfully, with over half of these (43/70) completing within the minimum period of 4 years. Of the 192 White/Asian students enrolled in the program, $155(80.7 \%)$ successfully completed the program, with 145 of these students completing within the minimum period of 4 years. The proportion of Black students with no record of completion of the program was higher $(35 / 105)$ than that of the White/Asian students (37/192). The records reviewed did not provide information about the final outcomes of these students.

\section{DISCUSSION}

While higher education in the country has generally undergone remarkable changes, the resilience of practices and ideas of the old SA regime remains the cause of immense frustration (Subotzky 2010). In spite of post-apartheid attempts to widen access to higher education, overall participation and graduation rates are still considered low, particularly among Black South Africans (Strydom et al 2010). Attempts to widen access and ensure positive educational outcomes in any academic program should give adequate consideration to the profile and specific needs of the student body anticipated to enroll in the program. Therefore this study reports on the preliminary steps taken to identify aspects or issues in the records of students who applied for admission and students who enrolled in the program, that should be addressed to obtain a more diverse student body in the undergraduate physiotherapy education program at UCT, and that all students admitted into the program are given the opportunity to succeed.

The number of applications received for the six cohorts would suggest that the high interest in the program at the university was still maintained. As of 1979, approximately 140 applications were received for 26 places (Jaholkowski 1979), while for the cohorts reviewed, there were 2753 applications for 287 places. There was little difference between the total number of Black applicants $(n=1299)$ and White/Asian applicants $(n=1454)$. From the records, it was found that most of the African and Asian applicants were resident in provinces outside of the Western Cape, whereas the Coloured and White applicants were mainly from the Western Cape Province. Being a national university, UCT strives to attract students from different parts of the country. However, only $12.5 \%(344 / 2753)$ of applications was from the Coloured population group, which is rather low for a population group that is predominant in the Western Cape Province.

Of the total applications received during the stipulated study period, only one quarter of the Black applicants met the minimum requirements for admis- sion into the undergraduate physiotherapy education program. This may be a direct result of the effect apartheid and the passing of unjust laws like the Bantu Education Act in 1953, had on the quality of education received by Blacks in SA (Subotzky 2010). The Bantu Education Act produced devastating effects on Blacks in SA, and attempts by the post-apartheid government to dismantle years of racial discrimination are still ongoing. Therefore the plan to widen access into the undergraduate physiotherapy education program should develop awareness and recruitment strategies that target applicants across the country, though paying greater attention to Black students.

Admission offers were made to $65 \%$ of the Black applicants who met the minimum requirements. This is a positive step towards improving access and equity. However, the enrolment rate among the same group of applicants was lower when compared with White/Asian applicants. One of the possible reasons for low enrolment rates by Black students in the program could be the high financial cost of studying at UCT (Kemp and Gounden 2000) which included fees related to application, alternate admission test, acceptance deposits, tuition, accommodation, and other miscellaneous fees and levies. The plan to widen access should therefore include strategies to address the factors that contribute to the low enrolment rate, and should provide information about sources of available financial support for Black students with financial constraints who may wish to take up admission offers.

The overall completion rate for Black students was lower than the average completion rate for the six cohorts, and about one quarter of these students spent between 5 to 6 years to complete the 4-year program. However, the average proportion of Blacks among graduating physiotherapists was higher than the national proportion in the graduation trends between 1995 and 2004 (South African Qualifications Authority 2007). The lower completion rate of Black students could also be attributed to drop outs or transfers to other programs. It is believed that the quantitative measurement of throughput rates fails to reflect 
the intricacies of social conditions and the teaching and learning process (Scott et al 2007). However, in spite of their limitations, these measurements are considered useful indicators of the need for deeper investigations. Students who applied for or were admitted into the undergraduate physiotherapy program were from positions of extreme inequalities in terms of high school experiences, socioeconomic resources and other opportunities. These inequalities have been cited as possible reasons why students fail or take longer to complete the programs for which they enrolled. This may neutralize the gains made in increasing access to Black students, and frustrate efforts to address equity in the workforce in SA.

Another possible reason for the performance of Black students may relate to their adjustment in a university formerly dominated by a "European academic culture", with different expectations from the students, academic staff, and other students from a wide range of school and life experiences (Mbambo 2005). Issues about race and difference, which had been largely invisible when UCT was socially homogenous, became visible and had to be addressed by both the students and staff of the university. The plan to widen access should therefore include strategies that address the academic and non-academic factors that influence the retention and throughput rates of the students enrolled in the undergraduate physiotherapy education program.

The plan to increase access should review the contextual challenges relating to academic success in order to identify what can be realistically done to adequately support students and improve their chances of attaining the qualification they seek. The contextual challenges include a review of the curriculum to decongest it if necessary, while ensuring the relevance and the high academic standard of all the courses offered. In addition, the pass rates of students in each of the courses should be reviewed to identify the ones in which students encountered difficulties, the factors that impeded the throughput of students, as well as the possible reasons why students dropped out of the program. Finally, the planning should propose appropriate academic support for academically under-prepared students who enroll for the program.

To achieve the goal of increasing access into the undergraduate physiotherapy education program at UCT, separate task teams were set up to facilitate the following processes - curriculum transformation, awareness raising and recruitment, academic support for under-prepared students, and student support in counseling. In 2009, the first cohort of students was admitted into the transformed program with changes in the profile of the students (Table 5). In addition, separate structures to assist students with academic and non-academic issues were established.

A major benefit of the outcome of this review of the records of students is the awareness about pieces of missing information about the students. Actions have been taken to ensure that we keep and update detailed records of our students.

\section{CONCLUSIONS}

The debates around access, retention and throughput of students in university education programs are still ongoing. From the pointers identified from the analysis of the records of 2000-2005 cohorts of students who applied for admission and those who enrolled, the planning for widening participation in terms of access to the undergraduate physiotherapy education program should include strategies to address the current schooling system to improve the access to quality education with specific focus on mathematics and the sciences for increasing the number of black candidates who could qualify to apply; increasing awareness and recruitment into the program; improving take up or enrolment rates of Black students by making financial support available to struggling students; and improving retention and throughput in the program by creating supportive environments cognizant of the cultural diversity.

\section{REFERENCES}

Cross M, Mungadi R, Rouhani S 2002 From policy to practice: curriculum reform in South African education. Comparative Education 38(2):171-187.

Department of Health 1997 White paper for the transformation of the health systems in South Africa. http://www.doh.gov.za/docs/policy-f.html (Accessed 24 July 2009).

Duncan M, Alperstein M, Mayers P, Olckers L, Gibbs T 2006 Not just another multi-professional course! Part 1. Rationale for a transformative curriculum. Medical Teacher 28(1):59-63.

Ensor P 2002 Curriculum. In: Cloete N, Fehnel R, Maassen P, Moja T, Perold H, Gibbon T (Eds) Transformation in Higher Education: Global pressures and local realities, pp270-295. Juta Academic Press, Cape Town.

Fraser WJ, Killen R 2003 Factors influencing academic success or failure of first-year and senior university students: do education students and lecturers perceive things differently? South African Journal of Education 23(4):254-263.

HPCSA 2009 Number of registered healthcare practitioners and registered healthcare students. http://www.hpcsa.co.za (Accessed 20 August 2010).

Jaholkowski BM 1979 Physiotherapy present and future. South African Medical Journal 55(13): 513-515.

Kemp S, Gounden P 2000 Production and distribution of physiotherapists in South Africa. HST Update 49:17-18.

Khalfani AK, Zuberi T 2001 Racial classification and the modern census in South Africa 1911-1996. Race and Society 4(2):161-176.

Louw Q, Grimmer-Somers K, Crous L, Marais M, Amosun SL 2007 Framing a vision for physiotherapy research: Synthesizing educators' viewpoints in Cape Town. Internet Journal of Allied Health Sciences and Practice 5(2):1-8.

Mbambo NP 2005 A report on case studies reflecting the experiences of Black physiotherapy students at institutions where they are minority. South African Journal of Physiotherapy 61(4):2-5.

Mooney G, McIntyre DE 2008 South Africa: A $21^{\text {st }}$ century apartheid in health and health care? Medical Journal of Australia 189(11/12):637-640. Nekhwevha F 1999 No matter how long the night, the day is sure to come: Culture and educational transformation in post-colonial Namibia and postapartheid South Africa. International Review of Education 45(5/6):491-506. 
Scott I, Yeld N, Hendry J 2007 Higher Education Monitor No 6: A case for improving teaching and learning in South African higher education. Council on Higher Education, Pretoria 2007 [accessed 18 Dec 2009]. Available from: http://www.che.ac.za/documents/d000155/index.php

South African Qualifications Authority (SAQA). Analysis of the National Learners' Records Database, Report 2. 2007; http://www.saqa.org.za/docs/ reports/hetrenz/2007/report.pdf (Accessed 20 May 2010).

Strydom F, Kuh G, Mentz M 2010 Enhancing success in South Africa's higher education: measuring student engagement. Acta Academica 42(1):259-275.

Subotzky G 2010 Enhancing retention and success in South Africa. International Higher Education 58:24-26.

Taylor B, Harris G 2004 Relative efficiency among South African universities: A data envelopment analysis. Higher Education 47:73-89.

Van der Westhuizen GJ 2005 Elusive equity: Reform in post-apartheid South Africa (Review). African Studies Review 48(3):184-186.

Winberg C 2006 Undisciplining knowledge production: development driven higher education in South Africa. Higher Education 51(2):159-72. 
